RESEARCH NOTE

\title{
Quality Attributes, Biochemical Profile and Calorific Status of Functional RTS Drink from a Blend of Mango and Tomato
}

\author{
Madhu Parmar ${ }^{1}$, Sonia Johri ${ }^{1 *}$, Hradesh Rajput ${ }^{2}$ and J.L. Bhat ${ }^{2}$ \\ ${ }^{1}$ Department of Life Sciences, ITM University, Gwalior, Madhya Pradesh, India \\ ${ }^{2}$ Department of Food Technology, ITM University, Gwalior, Madhya Pradesh, India \\ "Corresponding author: johrisonia@gmail.com
}

Paper No.: 239

Received: 24-06-2019

Revised: 28-10-2019

Accepted: 22-11-2019

\begin{abstract}
Fruits are rich sources of nutrients, macro molecules, good source of energy and a reservoir of antioxidants. In the present study, an attempt has been made to prepare a RTS (Ready-to-serve) functional food. Sensory evaluation of various combinations, followed by screening of the best combination was performed. Proximate analysis such as $\mathrm{pH}$, moisture content, ash content, total solid and Vitamin C content of the combination was estimated. Results of biochemical evaluation revealed that combination of mango: tomato in 50:50 followed by 60:40 proved to be the best combination. The phenolic and flavanoid content was the marker of the antioxidant status. The RTS proved to have a rich calorific value.
\end{abstract}

Keywords: Mango, RTS, tomato, fruits juice and phytochemicals

Fruits play a very important role in maintaining the nutritional status of the body. They are a reservoir of essential elements, such as water, vitamins (A, $\mathrm{B}_{1}, \mathrm{~B}_{2}, \mathrm{C}, \mathrm{D}$ and $\left.\mathrm{E}\right)$, minerals ( $\mathrm{Ca}, \mathrm{Mg}, \mathrm{Zn}, \mathrm{Fe}, \mathrm{K}$ etc.) and organic compounds which are very important for our body to make body function, (Okwu and Emenike, 2006; Dosumu et al. 2009). They are a good source of antioxidants which are the scavengers of free radicals. Because of rich perishability of fruits, they spoil quickly but can be preserved as beverages (Brett et al. 1996). Juices can be prepared by squeezing fresh fruits mechanically or by enzymatic extraction process. Fruit juices promote detoxification in the human body and contribute to good health (Minich and Bland, 2007). Natural sources of antioxidants from fruits are more advantageous to health than the synthetic counterparts or supplements (Liu, 2003). In the present era, consumer awareness towards the relationship between food and health has led to an explosion of interest in "healthy foods"; which could be partly attributed to the increasing cost of healthcare, the steady increase in life expectancy, and the desire of older people for an improved quality of life (Granato et al. 2010). Ready-to-serve (RTS) beverages are made out of fruits, such as pineapple, orange, lime, banana, litchi, passion fruit, and other local fruits which can be used for ready-to-serve (RTS) beverages preparations.

Mango has high nutritional value and is an important source of dietary antioxidants such as carotenoids, ascorbic acid and phenolic compounds (Manthey and Perkins, 2009). The phenolic compounds include flavonoids, phenolic acids, xanthones and

How to cite this article: Parmar, M., Johri, S., Rajput, H. and Bhat, J.L. (2019). Quality Attributes, Biochemical Profile and Calorific Status of Functional RTS Drink from a Blend of Mango and Tomato. Int. J. Food Ferment. Technol., 9(2): 149-154.

Source of Support: None; Conflict of Interest: None 
gallotannins (Kim et al. 2010) (Manthey and Perkins, 2009). The ascorbic acid is an important micronutrient acting as an antoxidant in the human diet is also known as neuroprotective agent (Du et al. 2012).

Tomato is among the fruit of the numerous cultivated varieties of Solanum lycopersicum. It is a rich source of ascorbic acid (vitamin C). Tomatos are known as a good source of phenolic compounds, pigments, like carotenoids antioxidants, and other nutrients in the human diet (Taveira et al. 2012).

The present study aims to prepare a ready-to-serve formulation (RTS) of combination of mango and tomato in different proportions.

\section{MATERIALS AND METHODS}

\section{Preparation of mango pulp and tomato juice}

Mango and tomato were procured from a local market of Gwalior, M.P. India. Fresh fully ripe mangoes were used for extraction of pulp. After washing the fruits were peeled cut into small pieces and then ground using laboratory grinder and the pulp was collected and heated at $80^{\circ} \mathrm{C}$ for 5 minutes and filled in sterilized bottles for further preparations. For preparation of tomato juice, fresh and ripe tomatoes were washed, dipped in hot water for removing the peels followed by juice extraction using laboratory juicer. For preservation, it was heated at $80{ }^{\circ} \mathrm{C}$ for 5 min and stored in sterilized bottles for further use.

\section{Preparation of Mango and Tomato RTS}

Preparation of Mango and Tomato (ready-to-serve) RTS. After preparation of mango pulp and tomato juices RTS were prepared in different formulations. In all the different formulations sugar, citric acid, black paper and salt were added in same proportion but the amount of mango pulp and tomato juices were different (Table 1). The mixture was filtered through muslin cloth. The prepared product was filled in sterilized glass bottles, sealed and sterilized at $100{ }^{\circ} \mathrm{C}$ for $15 \mathrm{~min}$, cooled and stored at room temperature for further study. The samples were screened on the basis of sensory evaluation and were further analyzed for their physicochemical and phyto-chemical properties.

Table 1: Different combination of RTS prepared by mango pulp and tomato juice

\begin{tabular}{ll}
\hline Sample No & Mango pulp: tomato juice \\
S1 & $100: 00$ \\
S2. & $90: 10$ \\
S3. & $80: 20$ \\
S4. & $70: 30$ \\
S5. & $60: 40$ \\
S6. & $50: 50$ \\
S7. & $40: 60$ \\
S8. & $30: 70$ \\
S9. & $20: 80$ \\
S10. & $10: 90$ \\
S11. & $0: 100$ \\
\hline
\end{tabular}

Physico-chemical Analysis of raw juice and RTS

Raw fruits and their processed products were analysed for various physico-chemical characteristics. Oven drying method described by the Association of Official Analytical Chemists (AOAC, 1990; Nielsen, 1998) was used for determination of moisture content and total solid. The Kjeldah method was used to determine the protein content (Rangana, 2005). The acidity was determined by titration using standard sodium hydroxide solution and expressed as anhydrous citric acid while $\mathrm{pH}$ was measured by a $\mathrm{pH}$ meter.

Dinitrosalicylic acid (DNSA) method was used to measure the reducing sugars as per the method of Miller (1959). Calorie content was calculated according to Recommended Dietary Allowance (RDA) as described here.

Calculation: Calorie $(\mathrm{kcal} / 100 \mathrm{~g})=($ Protein $\% \times 4)+$ $($ Fat $\% \times 9)+($ Carbohydrate $\% \times 4)$

Vitamin $C$ was determined by the titrimetric method using dichlorophenol indophenol dye (Ranganna 2005). Total phenolic content was determined by Colorimetric method of Folin-ciocalteau reagent (Singleton et al. 1999) using Gallic acid as a standard. 
Total flavonoid contents were measured by the aluminum chloride colorimetric method.

\section{Sensory evaluation of ready-to-serve (RTS)}

Sensory evaluation was done by 9 point hedonic scale. Panelists were selected from the teachers, student and employee of the department and were briefed before evaluating sensory quality of the samples. The panelists evaluated the color, flavor, mouth feel, and overall acceptability. The scale was arranged such that: $9=$ like extremely, $8=$ like very much, $7=$ like moderately, 6 = like slightly, 5 = neither like nor dislike, 4 = dislike slightly, 3 =dislike moderately, 2 = dislike very much, 1 = dislike extremely (Joshi, 2006).

\section{Statistical Analysis}

Results obtained from the physicochemical, phytochemical and sensory analysis were analysed and the means were presented Means+Standard deviation (S.D).

\section{RESULTS AND DISCUSSION}

\section{Sensory evaluation of ready-to-serve (RTS)}

The mean scores of sensory evaluation are presented on Table 2. In case of color preference among the samples, Sample S6 secured the highest score (7.3) and ranked as liked moderately while sample S7 score was 7.1. In case of flavor preference, sample S6 the most acceptable among two samples. Sample S6 secured the highest score 7.6 with moderately like ranking, followed by sample S7 (score $=7.4$ ) From (Table 2), Overall acceptability of sample S6 (7.8) was more than $S 7$ (6.4) thus, rendering it overall acceptability as highly acceptable. On the basis of sensory analysis it is conferred that mixed fruit juice (S6) containing 50\% mango, 50\% tomato juice secured the highest score followed by S7 in terms of color, flavor, sweetness and overall acceptability. This results are in confirmatory to those reported earlier (Sajeda Begum et al. 2018).

\section{Physico-chemical properties of raw juice and selected RTS}

The proximate analysis of the mango pulp revealed that, the moisture content to be $83 \%$, ash content $0.55 \%$, respectively and tomato juice contain moisture content $87.33 \%$ and total ash $0.45 \%$, respectively. Table 3 showed that sample S6 or S7 contained $92.4 \%$ and $95.46 \%$ water. This moisture value is less compared to the reported range of the mixed tropical fruit juice (Siti et al. 2017). The higher the moisture content of products, the more it is susceptible to spoilage by microbial action (Robert et al. 2002).

Table 2: Sensory evaluation of the different combination of RTS

\begin{tabular}{lllll}
\hline Sample & Colour & Mouth feel & Flavor & Overall Acceptability \\
\hline S1 & $6.05 \pm 0.42$ & $5.91 \pm 0.97$ & $5.28 \pm 1.13$ & $5.01 \pm 1.13$ \\
S2 & $6.71 \pm 0.45$ & $6.46 \pm 0.65$ & $6.26 \pm 0.66$ & $6.63 \pm 0.31$ \\
S3 & $6.11 \pm 0.77$ & $5.95 \pm 0.43$ & $6.08 \pm 0.92$ & $6.1 \pm 0.72$ \\
S4 & $6.88 \pm 0.22$ & $6.90 \pm 0.38$ & $7.08 \pm 0.56$ & $6.11 \pm 0.51$ \\
S4 & $6.95 \pm 0.37$ & $7.28 \pm 0.53$ & $6.16 \pm 0.52$ \\
S6 & $7.33 \pm 0.40$ & $8.05 \pm 0.60$ & $7.6 \pm 0.72$ & $7.88 \pm 0.40$ \\
S7 & $7.01 \pm 0.42$ & $7.06 \pm 0.36$ & $7.4 \pm 0.48$ & $6.43 \pm 0.61$ \\
S8 & $5.83 \pm 0.69$ & $6.50 \pm 0.34$ & $6.91 \pm 0.42$ & $6.05 \pm 0.50$ \\
S9 & $5.23 \pm 0.54$ & $5.98 \pm 0.51$ & $6.63 \pm 0.35$ & $5.5 \pm 0.50$ \\
S10 & $5.31 \pm 0.52$ & $5.65 \pm 0.65$ & $6.23 \pm 0.45$ & $4.86 \pm 0.44$ \\
S11 & $4.31 \pm 1.16$ & $4.13 \pm 0.43$ & $5.48 \pm 1.11$ & $5.50 \pm 1.36$ \\
\hline
\end{tabular}

Results are mean $\pm S D$. 
Table 3: Physico-chemical characteristics of mango pulp and tomato juice

\begin{tabular}{lllll}
\hline Parameter & Mango pulp & Tomato juice & S6 & S7 \\
\hline Crude Moisture (\%) & $83 \pm 3.60$ & $87.33 \pm 2.08$ & $92.40 \pm 1.64$ & $95.46 \pm 0.50$ \\
Crude Ash (\%) & $0.55 \pm 0.07$ & $0.45 \pm 0.110$ & $0.37 \pm 0.006$ & $0.320 \pm 0.010$ \\
Titratable acidity (\%) & $0.3 \pm 0.1$ & $0.05 \pm 0.01$ & $0.27 \pm 0.005$ & $0.23 \pm 0.01$ \\
Crude Total solid (\%) & $15.66 \pm 1.52$ & $12.66 \pm 1.15$ & $8.33 \pm 1.53$ & $4.78 \pm 0.70$ \\
Crude Protein (\%) & $0.55 \pm 0.9$ & $0.116 \pm 0.002$ & $0.45 \pm 0.01$ & $0.31 \pm 0.01$ \\
Crude Fat (\%) & $0.43 \pm 0.05$ & - & $0.30 \pm 0.1$ & $0.20 \pm 0.1$ \\
Crude Carbohydrates (\%) & $14.21 \pm 2.15$ & $34.70 \pm 8.62$ & $13.55 \pm 0.53$ & $13.17 \pm 0.85$ \\
pH & $4.32 \pm 0.39$ & $4.13 \pm 0.21$ & $4.157 \pm 0.232$ & $4.280 \pm 0.620$ \\
Calorie (kcal/100g) & $63.3 \pm 0.81$ & $138.4 \pm 0.91$ & $59.03 \pm 0.30$ & $55.53 \pm 1.30$ \\
\hline
\end{tabular}

Results are mean $\pm S D$.

Ash content of combination S6 was 0.38 and of S7 was 0.32 , respectively (Table 3 ). The results were more, similar to that reported by (Sajeda Begum et al. 2018) where $0.33 \%$ ash content was reported in orange juice. It was reported by (Harbers, 2002) that the ash contents of cherries, apple and tomatoes were $0.3,0.5$ and $0.6 \%$, respectively. The total ash content in food can be referred to the residue of inorganic substances such as minerals in a food (Pomeranz and Meloan, 1994). The higher ash content indicates higher mineral content (Monti et al. 2008).

Generally, some nutrients such as protein, fat and fiber will be slightly lower in fruit juice compared to its fresh fruit because these nutrients were reduced during the processing of the fruit juice (Mercola 2014). Fortification and enrichment of any nutrient can be carried out, if needed. In our study protein content was found to be $0.55 \%$, fat and carbohydrate content, ascorbic acid were $0.4 \%, 14.21 \%, 30.60$ $\mathrm{mg} / 100 \mathrm{~g}$ respectively in mango pulp. The tomato sample was found to contain protein content $0.116 \%$, carbohydrate $34.70 \%$, ascorbic acid $23.6 \mathrm{mg} / 100 \mathrm{~g}$. pH 4.13. Further, these results are more and less similar to the values reported by earlier Bello et al. (2016). Moisture content and ash content of tomato juice were $87 \%$ and $0.45 \%$, respectively. These results were in line with (Isabel Martınez-Valverde et al. 2002). Total solid content of tomato juice was $12.66 \%$. Total solid and $\mathrm{pH}$ of the mango pulp were $15.60 \%, 4.32$, respectively. The $\mathrm{pH}$ of the pulp was lower to the values of reported earlier (Ruhul Amin et al. 2018).

Tomato juice was also analyzed for its physicochemical parameters. Protein for combination S6 was $0.45 \%$ while that of 57 was $0.31 \%$ (Table 3 ). The highest protein was observed in sample S6 $(0.45 \%)$. Siti et al. (2017) reported a simiar protein content in Mixed Tropical Fruit Juice. Fat content in combination S6 was $0.3 \%$ while fat content in combination S7 was 0.2 $\mathrm{g}$ (Table 3). This also indicated that the combination of these fruit juices had very low fat content. The value of carbohydrate observed in combination S6 was $13.55 \%$ and S7 was $13.17 \%$ (Table 3). The juice was also low in calories, suitable to be included in diet. This was in line with reported value by (Morton, 1987) for Mango pulp to range between 16.2-17.8\%, respectively. (Ahmed and Ahmed, 2014) have reported that matured fruits were usually sweeter due to higher sugar content.

The carbohydrate content of any food product determines its energy (Nicolas et al. 2002). The $\mathrm{pH}$ value of the juice represents the degree of acidity and alkalinity of a substance. This indicated that the juice was in acidic condition and suitable to be served as ready to drink (RTD) beverages here.

Phytochemical properties of raw juice and selected RTS

Flavonoid and phenolic content of the mango pulp were $9.0 \mathrm{mg} / 100 \mathrm{~g}$ and $116 \mathrm{mg} / 100 \mathrm{~g}$, respectively. 
Phenolic content of tomato juice was $29.66 \mathrm{mg} / 100$. The results more or less similar to those reported value earlier (Gurpreet Kaur et al. 2016). In our study, the Vitamin C content was $30.60 \mathrm{mg} / 100 \mathrm{~g}$ in mango pulp. (Table 4). Vitamin C for combination (S6) was $15.33 \mathrm{mg} / 100 \mathrm{~g}$ and combination (S7) was $13.25 \mathrm{mg} / 100 \mathrm{~g}$ (Table 4). Higher Vitamin C content has been reported as $35.18 \mathrm{mg} / 100 \mathrm{~g}$ earlier (Gurpreet Kaur et al. 2016).

The value of phenolic content in combination S6 was $82.63 \mathrm{mg} / 100 \mathrm{~g}$ and combination S7 was $66.78 \mathrm{mg} /$ $100 \mathrm{~g}$ (Table 4). The result was more or less similar to that reported earlier (Gurpreet Kaur et al. 2016) where 84 to $98 \mathrm{mg} / 100 \mathrm{~g}$ phenolic compound in mix fruits and vegetable juice were estimated, respectively.

Table 4: Phytochemical properties of selected ready-to-serve (RTS)

\begin{tabular}{lllll}
\hline Parameter & $\begin{array}{l}\text { Mango } \\
\text { pulp }\end{array}$ & $\begin{array}{l}\text { Tomato } \\
\text { juice }\end{array}$ & S6 & S7 \\
\hline Ascorbic acid & $15.33 \pm$ & $13.25 \pm$ & $30.60 \pm$ & $23.6 \pm$ \\
$(\mathrm{mg} / 100)$ & 1.15 & 1.09 & 1.15 & 0.57 \\
& $5.77 \pm$ & $4.76 \pm$ & $9.0 \pm$ & $1.2 \pm$ \\
Flavonoid (mg /100g) & 0.40 & 2.08 & 0.20 & 0.20 \\
& $82.63 \pm$ & $66.78 \pm$ & $116 \pm$ & $29.66 \pm$ \\
Phenolic (mg of & 0.33 & 4.88 & 2.08 & 3.05 \\
\hline /100g) & & & & \\
\hline
\end{tabular}

Results are mean $+S D$.

Generally it is known that phenolic content are highly correlated with antioxidant activity and bioavailability of polyphenols (Manach et al. 2005). Phenolic compounds play vital role in the quality of processed food products like flavor and taste, they have specific and important health-promoting properties (Sharma et al. 2012). Flavonoid observed in combination S6 was $5.77 \mathrm{mg} / 100 \mathrm{~g}$ and combination S7 was $4.76 \mathrm{mg} / 100 \mathrm{~g}$, respectively (Table 4). Leposava et al. (2018) reported about flavonoid content in commercial apple juice was found to range from 5.53 to $5.55 \mathrm{mg} / \mathrm{l} \mathrm{QE}$. Flavonoids are natu1ral antidiabetic agents, which interfere with the production of free radicals and reduces oxidative stress.

The preparation of RTS drinks has been optimized here. Due to its nutritional values which can act as efficient energy booster and a potent antioxidant.

\section{REFERENCES}

A.O.A.C. 2000. Official methods of analysis of AOAC International $\left(17^{\text {th }}\right.$ ed.). Washington, DC: Association of Official Analytical Chemist.

Ahmed, O.K. and Ahmed, S.E.D 2014. Determination of optimum maturity index of mango fruits (Mangifera indica L.) in Darfur. Agriculture and Biology Journal of North America, 5(2): 97-103.

Bello, B.A, Jalaluddin, A. Khan, Rilwan, A., Adam, A.A., Sani, M.M., Ibrahim, S.I., Abdullahi, F.S. and Magaji A.S. 2016. Comparative proximate and some Micronutrients content of five local varieties of mango pulp (Mangifera indica) commonly consumed in Wudiltown Kano State. International Journal of Scientific \& Engineering Research, 7: 840.

Brend, Y., Galili, L., Badani, H., Hovav, R. and Galili, S. 2012. Total Phenolic Content and Antioxidant Activity of Red and Yellow Quinoa (Chenopodium quinoa Willd.) Seeds as Affected by Baking and Cooking Conditions. Food and Nutrition Sciences, 3: 1150-1155.

Brett, A., Cox, D.R.S., Simmons, R. and Anstee, G. 1996. Producing Solar Dried Fruits and Vegetables for Micro and Small Scale Rural Enterprise Development. Handbook 3: Practical Aspects of Processing. Chatham, UK.

Cartea, M.E., Francisco M., Soengasn and Velasco P. 2011. Phenolic compounds in Brassica vegetables. Molecules Basel Switzerland, 16(1): 251-280.

Dosumu, O.O., Oluwaniyi, O.O., Awolola, G.V. and Okunola, M.O. 2009. Stability studies and mineral concentration of some Nigerian packed fruit juices, concentrate and local beverages. African J. Food Sci., 3: 82-85.

Du, J., Cullen, J.J. and Buettner, G.R. 2012. Ascorbic acid: Chemistry, biology and the treatment of cancer. Biochimica et Biophysica Acta-Reviews on Cancer 1826(2): 443-457. doi: 10.1016/j.bbcan.2012.06.003

Granato, D., Branco, F.G., Nazzaro, F., Cruz, A.G. and Faria, J.A.F. 2010. Functional foods and nondairy probiotic food development: Trends, concepts, and products. Compr. Rev. Food Sci. Food Saf., 9: 292-302.

Gurpreet Kaur, Poonam Aggarwal and Hradesh Rajput. 2016. Development and Storage Stability of Thermally Processed Mixed Vegetable Ready to Serve (RTS) Juice. Indian Horticulture Journal, 6(3): 338-342.

Harbers, L.B. 2002. Ash content determination .Introduction to the chemical analysis of food. New Delhi (India), pp. 113-115.

Harris, W.M. and Spurr, A.R. 1969. Chromoplasts of tomato fruits-II. The red tomato. Am. J. Bot., 56: 380-389. 
Ikram, E.H K., Eng, K.H., Mohd Jalil A.M., Amin I., Salma I., Azrina A. and Ruzaidi Azli, M.H. 2009. Antioxidant capacity and total phenolic content of Malaysian underutilized fruits. Journal of Food Composition and Analysis, 22: 388-393.

Isabel Martı'nez-Valverde, Marıa J Periago, Gordon Provan and Andrew Chesson. 2002. Phenolic compounds, lycopene and antioxidant activity in commercial varieties of tomato (Lycopersicum esculentum).Journal of the Science of Food and Agriculture, 82: 323-330.

Joshi, V.K. 2006. Sensory Science: Principles and Applications in Evaluation of Food. Agro-Tech Publishers, Udaipur, pp. 527 + Plates, Figs.

Kim, H., Moon, J.Y., Kim, H., Lee, D.S., Cho, M., Choi, H.K., Kim, Y.S., Mosaddik, A. and Cho, S.K. 2010. Antioxidant and antiproliferative activities of mango (Mangifera indica L.) flesh and peel. Food Chemistry, 121(2): 429-436.

Leposava PAVUN, Snežana Uskoković-Marković, Milena Jelikić-Stankov, 2018. Contents in Commercial Apple Juices. Czech J. Food Sci., 36(3): 233-238.

Liu, R.H. 2003. Health benefits of fruit and vegetables are from additive and synergistic combinations of phytochemicals. American Journal of Clinical Nutrition, 78(Suppl.), 517S-20S.

Malaysian Food Act (1983) and Food Regulations (1986). Food Regulations. Malaysia: MDC Publisher.

Manach, C., Williamson, G., Morad, C., Scalbert, A. and Remesy, C. 2005. Bioavailability and bioefficacy of polyphenols in humans. 1. Review of 97 bioavailability studies. American Journal of Clinical Nutrition, 81: 230S-242S.

Manach, C., Williamson, G., Morad, C., Scalbert, A. and Remesy, C. 2005. Bioavailability and bioefficacy of polyphenols in humans. 1. Review of 97 bioavailability studies. American Journal of Clinical Nutrition, 81: 230S-242S.

Manthey, J.A. and Perkins, P. 2009. Influences of harvest date and location on the levels of $\beta$-carotene, ascorbic acid, total phenols, the in vitro antioxidant capacity, and phenolic profiles of five commercial varieties of mango (Mangifera indica L.). Journal of Agricultural and Food Chemistry, 57(22): 10825-10830.

Mercola, J. 2014. Juicing: How healthy is it? Retrieved November 16, 2016, from http://articles.mercola.com/ sites/ articles/archive/2014/04/19/juicing-benefits.aspx.

Miller, G.L. 1959. Use of Dinitrosalicylic Acid Reagent for Determination of Reducing Sugar. Analytical Chemistry, 31: 426-428.

Minich, D.M. and Bland, J.S. 2007. Acid-alkaline balance: role in chronic disease and detoxification. Alternat. Therapies Health Med., 13: 62-65.

Monti, A., Virgilio, N.D. and Venturi, G. 2008. Mineral composition and ash content of six major energy crops. Biomass and Bioenergy, 32(3): 216.

Morton, J. 1987. Mango Fruits. Mango In: Fruits of Warm Climate. Jullia F. Morton, Miami, FL., pp. 22 1-239.
Nicolas, H.L. 2002. Carbohydrates Analysis. Introduction to the chemical analysis of food. New Delhi (India), pp. 139.

Nielsen, S.S. 1998. Introduction to Food Analysis techniques. Text Book. Aspen Pub. USA.

Okwu, D.E. and Emenike. I.N. 2006. Evaluation of the phytonutrients and vitamin contents of citrus fruits. Int. J. Mol. Med. Adv. Sci., 2: 1-6.

Pomeranz, Y. and Meloan, C.E. 1994. Ash and Minerals. Food Analysis: Theory and Practice, 3: 602-624.

Ranganna, S. 2005. Hand Book of Analysis of Quality Control for Fruit and Vegetable Products. Second edition. Tata McGraw Hill Publications Company Limited, New Delhi, India.

Rattanaporn, M., Sombat, S. and Suchada, V. 2005. Influence of packaging materials and storage time on chemical components of rice seed viability. Conference on Inter. Agric. Res. For Development, October, 11-13. Post-harvest Technology Institute, Graduate School, Chiang Mai University, Chiang Mai, 50200, Thailand.

Robert, L.B. and Bradly, L. 2002. Moisture And total Solid Content. Determination Introduction to the chemical analysis of food. New Delhi (India), pp. 95.

Ruhul Amin, Shafkat, S. Rahman, Mahboob Hossain and Naiyyum Choudhury. 2018. Physico-chemical and Microbiological Qualities Assessment of Popular Bangladeshi Mango Fruit Juice. The Open Microbiology Journal, 12: 135-147.

Sajeda Begum, Pabitra Chandra Das and Poly Karmoker. 2018. Processing of mixed fruit juice from mango, orange and pineapple. Fundamental and Applied Agriculture, 3(2): 440-445.

Scalbert, A., Manach, C. and Morand, C. 2005. Dietary Polyphenols and the Prevention of Diseases. Critical Reviews in Food Science and Nutrition, 45: 287-306.

Sharma, M., Gehlot, R., Singh, R. and Siddiqui, S. 2012. Changes in chemical constituents and overall acceptability ofguava jamun blend RTS drink and squash during storage. Beverage Food World, 39: 39-42.

Singleton, V.L., Orthofer, R. and Lamuelaraventós, R.M. 1999. Analysis of total phenols and other oxidation substrates and antioxidants by means of Folin-Ciocalteu reagent. Methods Enzymology, 299: 152-178.

Siti Nur Aqilah Abdul Malek, Hasnah Haron, Wan Aida Wan Mustapha and Suzana Shahar. 2017. Physicochemical Properties, Total Phenolic and Antioxidant Activity of Mixed Tropical Fruit Juice, TP 3 in 1 TM. Journal of Agricultural Science, 9.

Taveira, M., Ferreres, F., Gil-Izquierdo, A., Oliveira, L., Valentao, P. and Andrad, P.B. 2012. Fast determination of bioactive compounds from Lycopersicon esculentum Mill. leaves, Food Chemistry, 135(2): 748-755. 